\title{
Fatores que interferem durante o processo de fermentação natural das fatias de cubiu
}

\section{Factors that interfere in the process of natural fermentation of the cubiu slices \\ Factores que interfieren en el proceso de fermentación natural de rodajas de cocona}

\author{
Nascimento de Oliveira F, Francisca Marta Freitas ${ }^{1 *}$ Ph.D, De Souza A, Jerusa ${ }^{2}$ Ph.D, \\ Gomezcaceres P, Luty ${ }^{3}$ M.Sc.
}

${ }^{1}$ Universidade Nilton Lins, Brasil.

${ }^{2}$ INPA, Brasil.

${ }^{3}$ CECAR, Colombia.

\section{Keywords:}

Solanum sessiliflorum Dunal; blanching;

physical and physical-chemical properties; microbiology.
Palavras chave:

Solanum sessiliflorum Dunal; branqueamento; propriedades físicas e físicoquímicas; microbiologia.
INFORMACIÓN

Recibido: 27-06-2016;

Aceptado: 12-12-2016.

Correspondencia autor:

fmartaagri@hotmail.com

\section{Abstract}

This study aims to assess the effects of natural fermentation on the physical, physicchemical and microbiological cubiu. Ripe cubiu undergone selection, peel, cut into four pieces, seeds removed and the slices were divided into two lots. One batch was subjected to blanching by immersion in water for 1 minute at $95^{\circ} \mathrm{C}$ and immediately bathed in ice water. Both were subjected to natural fermentation with increasing concentrations (2, 4, 6 and $8 \%) \mathrm{NaCl}$ and $24 \mathrm{~h}$ time of immersion in each concentration. The process was monitored by moisture, $\mathrm{pH}$, total acidity, sodium chloride, pectin and texture of the slices of cubiu. In relation to fresh fruit, money not increase the moisture and $\mathrm{pH}$, decrease in total acidity and sodium and chloride did not significantly alter the texture. During the process of natural fermentation parameters moisture, acidity, texture and $\mathrm{pH}$ (control) were reduced from their values for $\mathrm{pH}$ (bleached) and sodium chloride was no increase in the values. The natural fermentation process was detected during the immersion of slices of cubiu pre treated or not in $\mathrm{NaCl}$ solutions. The physical and physic-chemical properties of slices cubiu were modified during the natural fermentation process, being more pronounced in slices.

\section{Resumen}

O objetivo foi avaliar os efeitos da fermentação natural nas características físicas, físico-químicas e microbiológicas do cubiu. Frutos maduros passaram por seleção, descasque, corte em quatro partes, retirada das sementes e as fatias foram divididas em dois lotes. Um dos lotes foi submetido ao branqueamento por imersão durante 1 minuto em água a $95^{\circ} \mathrm{C}$ e imediatamente em banho de água com gelo e outro lote não tive branqueamento. Ambos foram submetidos à fermentação natural com concentrações crescentes (2, 4, 6 e $8 \%$ ) de $\mathrm{NaCl}$ e tempo de 24 h de imersão em cada concentração. O processo foi monitorado pelas análises de umidade, $\mathrm{pH}$, acidez total, cloreto de sódio, textura e pectina das fatias do cubiu. Em relação ao fruto in natura, o branqueamento acarretou aumento da umidade e $\mathrm{pH}$, decréscimo da acidez total e do cloreto de sódio e não alterou significativamente a textura. Durante o processo de fermentação natural os parâmetros umidade, acidez total, textura e pH (controle) sofreram redução, para pH (branqueadas) e cloreto de sódio houve acréscimo. O processo de fermentação natural foi detectado durante a imersão das fatias do cubiu pré tratado ou não em soluções de cloreto de sódio $(\mathrm{NaCl})$. As características físicas e físico-químicas das fatias de cubiu sofreram modificações no processo de fermentação natural, sendo mais acentuadas nas fatias pré tratadas. 


\section{Introdução}

O cubiu (Solanum sessiliflorum Dunal) pertence à família das Solanaceae, nativa da Amazônia Ocidental e presente em toda a Amazônia Brasileira, Peruana e Colombiana YUYAMA et al. (2007). O cubiu é uma planta rústica, fácil de ser cultivada e muito produtiva, podendo atingir 100 toneladas de frutos por hectare, dependendo do genótipo cultivado, e assim, sob o ponto de vista econômico, torna-se uma matériaprima importante para a agroindústria SILVA FILHO et al.(2005). Seus frutos apresentam altos teores de umidade e de acidez, limitando, respectivamente, a conservação pós colheita e o consumo in natura. ANDRADE Júnior (2006) verificou que, independente do estádio de maturação, o cubiu apresenta altos teores de pectinas, o que é desejável quanto ao aspecto nutricional, mas que dificulta a incorporação de solutos no processo de desidratação osmótica.

A aplicação de pré tratamentos, como o branqueamento e a fermentação natural, acarreta modificações, em diferentes graus, na resistência da parede celular para o fluxo de água e na integridade das membranas NIETO et al., (2001), podendo serem utilizados antes dos processos osmóticos para favorecer a incorporação dos solutos.

O branqueamento é um pré tratamento que propicia o cozimento parcial do tecido vegetal, promovendo mudanças nos polímeros de pectina da parede celular e lamela média CANET et al. (2005), tornando a membrana celular mais permeável à passagem de vapor de água, induzindo, no caso de secagem posterior, em maiores taxas de secagem e melhor textura do produto (AGUIRRE et. al. 1982), além de inativar enzimas cuja atividade implica no desenvolvimento de cor, sabor e odor indesejáveis (LUíZ et al., 2007).

A fermentação natural em frutos rígidos é um pré tratamento que causa a hidrólise das pectinas pela ação das enzimas bacterianas, favorecendo ao açucaramento, a perda da firmeza e uma parcial desidratação dos frutos, evitando assim, o enrugamento durante um posterior processo de secagem e proporcionando ao produto final uma desejável plasticidade e translucidez (JACKIX, 1988).

Para preservar as características do fruto e suas propriedades funcionais, variar a forma de uso e facilitar a aceitação é necessário o emprego de tecnologias de processamento (OLIVEIRA et al., 2008). No entanto, qualquer que seja o processamento, por mais simples que seja, traz consequências nas características físicas, químicas, físico-químicas e nutricionais (GOMEZ CACERES et al., 2009), sendo imprescindível estudar as alterações nas características física e físicoquímicas.
Vários estudos foram desenvolvidos sobre o cubiu até o presente momento, como obtenção e conservação da polpa (OLIVEIRA, 2002), elaboração de néctar (OLIVEIRA, 1999), geléia convencional (MACEDO, 1999), geléia dietética (YUYAMA et al., 2008) e uso de soluções ternárias para produção de fruto desidratado (GOMEZ CACERES, 2010). Estes estudos tiveram como objetivo ampliar o interesse no cultivo do cubiu para a expansão dos Arranjos Produtivos Locais, para uso na formulação de alimentos (GOMEZ CACERES et al., 2008) e na elaboração de novos produtos, podendo proporcionar uma nova fonte de renda para a população da região.

Diante do exposto, este estudo tem por objetivo avaliar os efeitos da fermentação natural nas características física, físico-química e microbiológica das fatias de cubiu.

\section{Material e métodos}

Os experimentos foram desenvolvidos no Laboratório de Bioquímica de Alimentos e Fisiologia Pós-colheita do Instituto Nacional de Pesquisas da Amazônia (INPA) e no Laboratório de Fermentação da Universidade Federal do Amazonas (UFAM).

Frutos de cubiu foram colhidos maduros de plantas cultivadas na Estação experimental do Ariaú, pertencente ao INPA. Estes passaram pelas etapas de seleção, lavagem, sanitização por imersão durante 15 minutos em solução de hipoclorito de sódio a $0,02 \%$, enxágue, descasque manual com faca de aço inoxidável, fatiamento pelo corte do fruto em quatro partes, e retirada das sementes. As fatias foram divididas em dois lotes, sendo o primeiro submetido ao branqueamento e fermentação natural e o segundo lote submetido a fermentação natural, porém, sem o prévio branqueamento (controle).

O branqueamento consistiu na imersão das fatias durante um minuto em água a $95^{\circ} \mathrm{C}$ e imediatamente em banho de água com gelo (OLIVEIRA, 2002). A fermentação natural foi conduzida por imersão em soluções com concentrações crescentes de 2, 4, 6 e $8 \%$ de $\mathrm{NaCl}$. O tempo de permanência em cada concentração foi de $24 \mathrm{~h}$, a proporção fatias: salmoura foi de 1:10 e a temperatura média do ambiente foi mantida em $26{ }^{\circ} \mathrm{C} \pm 0,82$. Embalagens flexíveis (sacos de plásticos) cheias de água e fechadas hermeticamente foram colocadas sobre as fatias, na superfície da cuba de fermentação, para garantir a total e permanente imersão das fatias durante todo o processo.

As avaliações físicas e físico-químicas (textura, $\mathrm{pH}$, acidez total, cloreto de sódio, e pectina) foram realizadas antes (in natura) e após os processos de 
branqueamento e fermentação natural, bem como durante todo o processo de fermentação natural. A textura das fatias foi determinada através do texturômetro Texture analyser da marca Stable Micro Systems e modelo TA-XT2, utilizando pedaços do mesocarpo do cubiu medindo $1 \times 3 \times 1 \mathrm{~cm}$. Todas as leituras foram realizadas com a superfície interna voltada para cima (para a sonda) e as condições de operação para medida de força e compressão foram: sonda cilíndrica de $40 \mathrm{~mm}$; distância de $4 \mathrm{~mm}$; velocidades de 2, 1 e $5 \mathrm{~mm} / \mathrm{s}$ para pré-ensaio, ensaio e pós-ensaio, respectivamente. $\mathrm{O} \mathrm{pH}$ foi medido em potenciômetro e a acidez por titulação com solução de $\mathrm{NaOH} 0,1 \mathrm{~N}$ e fenolftaleína como indicador; os teores de cloreto de sódio foram determinados segundo o Método de Mohr, baseado na titulação com nitrato de prata e cromato de potássio como indicador (INSTITUTO ADOLFO LUTZ, 2008). A pectina foi determinada pelo método de Carbazol descrita por Southgate (1991), a partir dos sólidos insolúveis em álcool - AIS (CANTOR et al., 1992).

A confirmação do processo de fermentação natural foi avaliada através do cultivo em meios apropriados para crescimento microbiano em condições assépticas. Os meios de cultura utilizados nos cultivos foram: Batata Dextrose Ágar (BDA) para leveduras, Ágar Sabouraud Dextrose para fungos filamentosos e Ágar Nutriente para bactérias.

Os meios de cultura foram preparados e esterilizados conforme indicação do fabricante. Após a esterilização foram adicionados cerca de $150 \mathrm{mg} / \mathrm{L}$ de meio do antibiótico clorofenicol ao meio BDA; $100 \mu \mathrm{g} / \mathrm{mL}$ de burlate = DMSO - Dimetilsulfóxido (fungicida) ao meio Ágar nutriente, e $400 \mathrm{mg} / \mathrm{L}$ meio de cicloexamida + $150 \mathrm{mg} / \mathrm{L}$ meio de clorofenicol ao meio Ágar Sabouraud.

$\mathrm{Na}$ análise foram utilizadas amostras das fatias de cubiu in natura e após fermentação natural, pré tratada (branqueada) ou não (controle). Para o preparo, $10 \mathrm{~g}$ das fatias foram misturadas com $90 \mathrm{~g}$ do Tampão PBS (8g NaCl, 0,2g KCl, 1,44g Na $\mathrm{HPO}_{4}, 0,24 \mathrm{~g} \mathrm{KH}_{2} \mathrm{PO}$, $1 \mathrm{~L}$ de água destilada), conforme metodologia descrita em Gava (2002). Estas misturas foram mantidas em agitação durante 30 minutos em Shaker a $100 \mathrm{rpm}$ a temperatura a $26{ }^{\circ} \mathrm{C}$. Após este período foi retirado 0,1 $\mathrm{mL}$ da solução contendo amostra mais Tampão PBS para inocular as placas contendo os diferentes meios. As placas em triplicatas foram incubadas por 48 horas em estufa tipo BOD com temperatura de $37 \pm 1^{\circ} \mathrm{C}$.

Os dados experimentais foram analisados estatisticamente através do programa computacional ASSISTAT, versão 7.5 beta (SILVA e AZEVEDO, 2002). A comparação entre médias foi feita pelo teste de Tukey a $5 \%$ de probabilidade.

\section{Resultados}

Nas fatias de cubiu in natura e após o tratamento por imersão em soluções de $\mathrm{NaCl}$, previamente branqueadas ou não (controle), foram detectadas a presença de diferentes microrganismos, conforme pode-se observar nas Figs. 1, 2 e 3.

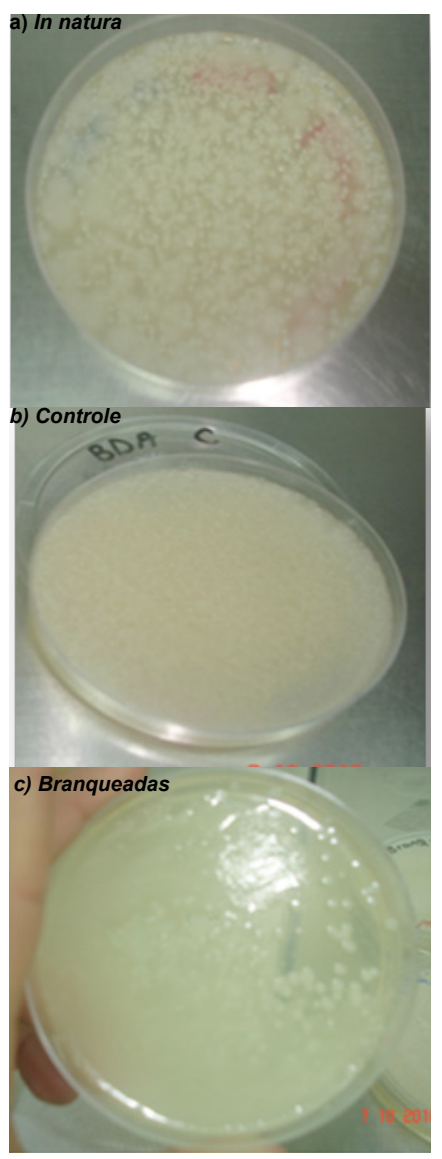

Figura 1. Presença de microrganismos após $24 \mathrm{~h}$ de cultivo em meio de cultura BDA e isolados de amostras de fatias de cubiu in natura (a), controle (b) e branqueadas (c).

O crescimento de leveduras foi observado as 24 horas, nas amostras que foram branqueadas e fermentadas, as amostras somente fermentadas no tiveram crescimento as 24 horas, mais as 48 horas o crescimento foi abundante em todas.

O crescimento de microrganismos no ágar nutritivo foi primeiramente observado nas amostras in natura, mas as 48 horas todas as placas apresentavam crescimento abundante. 


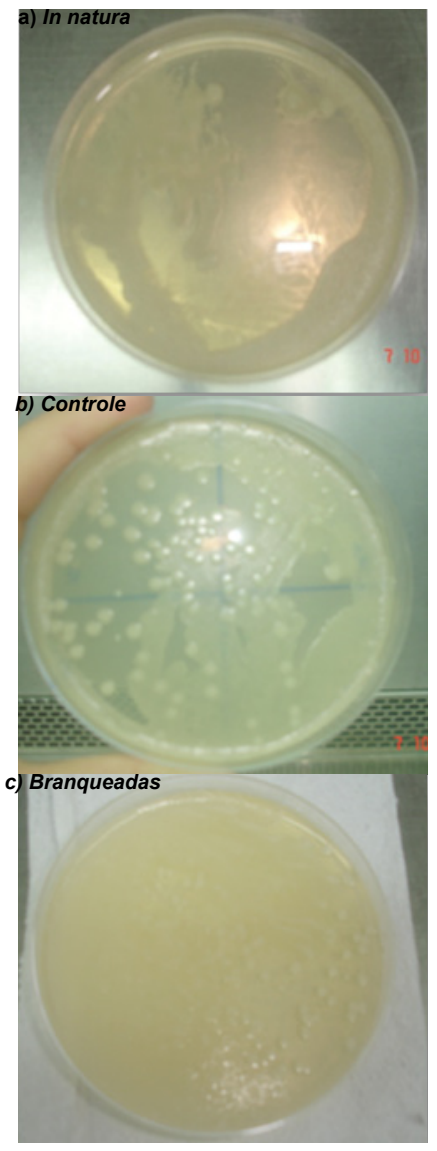

Figura 2. Presença de microrganismos após 24 h de cultivo em meio de cultura Ágar Sabouraud e isolados de amostras de fatias de cubiu in natura (a), controle (b) e branqueadas (c).
Os valores médios da umidade, $\mathrm{pH}$, acidez total, cloreto de sódio, textura e pectina das fatias de cubiu in natura e após o branqueamento estão ilustrados na Tabela 1. Observa-se que houve diferença estatística entre os tratamentos estudados ao nível de $5 \%$ de probabilidade pelo teste de Tukey, exceto para textura.

Observa-se que os coeficientes de variação de todos os parâmetros avaliados foram inferiores a 4,7 \%; portanto, considerados baixos (<5\%), segundo classificação de SANTOS et al. (2003), significando que as análises realizadas apresentaram ótima precisão experimental.

Tabela 1 - Valores médios de umidade, $\mathrm{pH}$, acidez, cloreto de sódio, textura e teor de pectinas das fatias de cubiu in natura e após o branqueamento

\begin{tabular}{lccccc}
\hline \multicolumn{1}{c}{ Parâmetros } & In natura & $\begin{array}{c}\text { Após } \\
\text { branqueamento }\end{array}$ & $\begin{array}{r}\text { Média } \\
\text { geral }\end{array}$ & DMS & C.V. (\%) \\
\hline Umidade (\%) & $92,45 \mathrm{~B}$ & $93,39 \mathrm{~A}$ & 92,92 & 0,73 & 0,34 \\
$\mathrm{pH}$ & $4,36 \mathrm{~B}$ & $4,84 \mathrm{~A}$ & 4,59 & 0,02 & 0,23 \\
$\begin{array}{l}\text { Acidez total } \\
\text { (mL de NaOH) }\end{array}$ & $13,81 \mathrm{~A}$ & $5,29 \mathrm{~B}$ & 9,54 & 0,89 & 4,14 \\
$\begin{array}{l}\text { Cloreto de sódio } \\
\text { (\% NaCl) }\end{array}$ & $0,32 \mathrm{~A}$ & $0,13 \mathrm{~B}$ & 0,23 & 0,02 & 4,67 \\
$\begin{array}{l}\text { Textura (N) } \\
\begin{array}{l}\text { Pectinas } \\
\text { (mg/100g) }\end{array}\end{array}$ & 26,93 A & $25,99 \mathrm{~A}$ & 26,46 & 2,39 & 3,98 \\
\hline
\end{tabular}

DMS - Desvio mínimo significativo; C. V. - Coeficiente de variação.

As médias seguidas pela mesma letra não diferem estatisticamente entre si. Foi aplicado o Teste de Tukey ao nível de $5 \%$ de probabilidade.

Os valores médios do teor de umidade das fatias de cubiu durante o processo de fermentação natural são demonstrados na Tabela 2. Pode-se observar que a

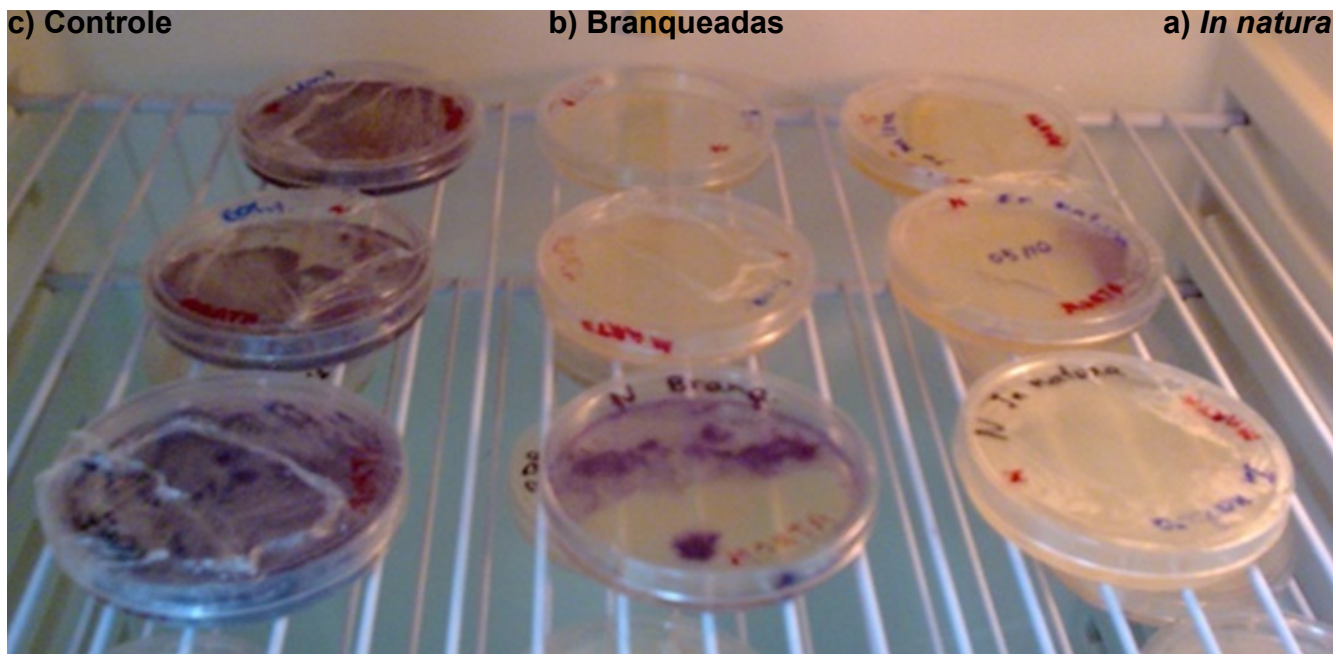

Figura 3. Presença de microrganismos após 24 h de cultivo em meio de cultura Ágar Nutritivo e isolados de amostras de fatias de cubiu in natura (a), controle (c) e branqueadas (b). 
fermentação natural reduziu os teores de umidade em relação aos frutos in natura. O controle apresentou diminuição de umidade superior em comparação as fatias pré tratadas com branqueamento, isto era esperado já que após o branqueamento, houve um aumento do teor de umidade das fatias (Tabela 1).

Tabela 2. Valores médios do teor umidade das fatias de cubiu durante o processo de fermentação natural.

\begin{tabular}{ccc}
\hline \multirow{2}{*}{$\begin{array}{c}\text { Concentração das soluções } \\
(\% \mathrm{NaCl})\end{array}$} & \multicolumn{2}{c}{ Umidade (\%) } \\
\cline { 2 - 3 } & Controle & Branqueadas \\
\hline 2 & $90,58 \mathrm{aB}$ & $93,94 \mathrm{aA}$ \\
4 & $89,27 \mathrm{bB}$ & $93,74 \mathrm{aA}$ \\
6 & $88,14 \mathrm{cB}$ & $91,37 \mathrm{bA}$ \\
8 & $87,82 \mathrm{cB}$ & $90,04 \mathrm{cA}$ \\
\hline
\end{tabular}

Os tratamentos diferiram estatisticamente entre si ao nível de $5 \%$ de probabilidade pelo teste de Tukey, exceto no controle imerso nas concentrações das soluções 6 e $8 \%$, e nas fatias pré tratadas por branqueamento imersas nas concentrações das soluções 2 e $4 \%$.

As médias seguidas pela mesma letra minúscula na coluna e maiúscula na linha não diferem estatisticamente entre si. Foi aplicado o Teste de Tukey ao nível de 5\% de probabilidade

$\mathrm{Na}$ Tabela 3 são indicados os valores médios do $\mathrm{pH}$ das fatias de cubiu durante o processo de fermentação natural. Nota-se que para o controle, não houve uma tendência definida de acréscimo ou decréscimo em função do aumento da concentração da solução. Já nas fatias branqueadas essa tendência é de acréscimo.

Tabela 3. Valores médios do $\mathrm{pH}$ das fatias de cubiu durante o processo de fermentação natural.

\begin{tabular}{ccc}
\hline \multirow{2}{*}{$\begin{array}{c}\text { Concentração das soluções } \\
(\% \text { NaCl) }\end{array}$} & \multicolumn{3}{c}{$\mathbf{p H}$} \\
\cline { 2 - 3 } & Controle & Branqueadas \\
\hline 2 & $4,28 \mathrm{aA}$ & $4,13 \mathrm{cB}$ \\
4 & $4,23 \quad \mathrm{dA}$ & $4,19 \mathrm{cA}$ \\
6 & $4,46 \mathrm{bB}$ & $4,62 \mathrm{bA}$ \\
8 & $4,39 \mathrm{cB}$ & $4,88 \mathrm{aA}$ \\
\hline
\end{tabular}

Os valores médios do $\mathrm{pH}$ das fatias de cubiu branqueadas, ou não, diferiram estatisticamente pelo teste de Tukey a nível de $5 \%$ de probabilidade, exceto para os tratamentos imersos na solução de cloreto de sódio a $4 \%$, e para o tratamento submetido ao branqueamento entre as soluções de 2 e $4 \%$.

As médias seguidas pela mesma letra minúscula na coluna e maiúscula na linha não diferem estatisticamente entre si. Foi aplicado o Teste de Tukey ao nível de 5\% de probabilidade
$\mathrm{Na}$ Tabela 4 estão expostos os valores médios da acidez total das fatias de cubiu obtidos durante o processo de fermentação natural. Constata-se que os valores médios da acidez total diferem estatisticamente a nível de $5 \%$ de probabilidade pelo teste de Tukey, mas para o tratamento previamente submetido ao branqueamento, a acidez total permaneceu estatisticamente inalterada entre as soluções de $2 \%$ e $4 \%$, e também, entre as soluções de 4, 6 e $8 \%$.

Tabela 4. Valores médios da acidez total das fatias de cubiu durante o processo de fermentação natural.

\begin{tabular}{cccc}
\hline \multirow{2}{*}{$\begin{array}{c}\text { Concentração das soluções } \\
(\% \mathrm{NaCl})\end{array}$} & \multicolumn{2}{c}{ Acidez total $(\mathbf{m L}$ de $\mathrm{NaOH})$} \\
\cline { 2 - 4 } & Controle & Branqueadas \\
\hline 2 & $11,99 \mathrm{aA}$ & $1,05 \mathrm{aB}$ \\
4 & $8,93 \mathrm{bA}$ & $0,55 \mathrm{abB}$ \\
6 & $4,59 \quad \mathrm{cA}$ & $0,39 \quad \mathrm{bB}$ \\
8 & 3,88 & $\mathrm{dA}$ & $0,31 \quad \mathrm{bB}$ \\
\hline
\end{tabular}

Os percentuais de redução da acidez após o término do processo de fermentação em relação aos frutos in natura foram de 71,90\% (Controle) e 97,75\% (branqueadas).

A acidez total dos dois tratamentos diminuiu à medida que aumentou a concentração de cloreto de sódio da solução de imersão. Uma explicação para este fato é que, a diferença de concentração entre as fatias e a solução de $\mathrm{NaCl}$ ocasiona a saída de solutos naturais, tais como os ácidos orgânicos.

As médias seguidas pela mesma letra minúscula na coluna e maiúscula na linha não diferem estatisticamente entre si. Foi aplicado o Teste de Tukey ao nível de 5\% de probabilidade

$\mathrm{Na}$ Tabela 5 são apresentados os valores médios detectados de cloreto de sódio das fatias de cubiu durante o processo de fermentação natural. Observase que houve diferença estatística entre os tratamentos avaliados ao nível de $5 \%$ de probabilidade pelo teste de Tukey.

Tabela 5. Valores médios do cloreto de sódio das fatias de cubiu durante o processo de fermentação natural.

\begin{tabular}{cccccc}
\hline \multirow{2}{*}{$\begin{array}{c}\text { Concentração das soluções } \\
(\% \text { NaCl) }\end{array}$} & \multicolumn{3}{c}{ Cloreto de sódio (\% Nacl) } \\
\cline { 2 - 5 } & \multicolumn{2}{c}{ Controle } & \multicolumn{3}{c}{ Branqueadas } \\
\hline 2 & 1,03 & $\mathrm{~dB}$ & 1,48 & $\mathrm{dA}$ \\
4 & 2,75 & $\mathrm{cB}$ & 3,10 & $\mathrm{cA}$ \\
6 & 3,57 & $\mathrm{bB}$ & 6,26 & $\mathrm{bA}$ \\
8 & 5,46 & $\mathrm{aB}$ & \multicolumn{2}{c}{7,02} & $\mathrm{aA}$ \\
\hline
\end{tabular}

As médias seguidas pela mesma letra minúscula na coluna e maiúscula na linha não diferem estatisticamente entre si. Foi aplicado o Teste de Tukey ao nível de 5\% de probabilidade 
Na Fig. 4 são apresentados os valores da textura em função da concentração do cloreto de sódio das soluções. Pode-se observar que houve diminuição da textura proporcional ao aumento da concentração da solução. As perdas maiores foram nas fatias previamente tratadas com branqueamento, ocasionado pelo amolecimento devido à degradação térmica.

Os tratamentos diferiram estatisticamente entre si ao nível de $5 \%$ de probabilidade pelo teste de Tukey, exceto na concentração da solução de $8 \%$ que não existe diferença entre o controle o as fatias pré branqueadas.

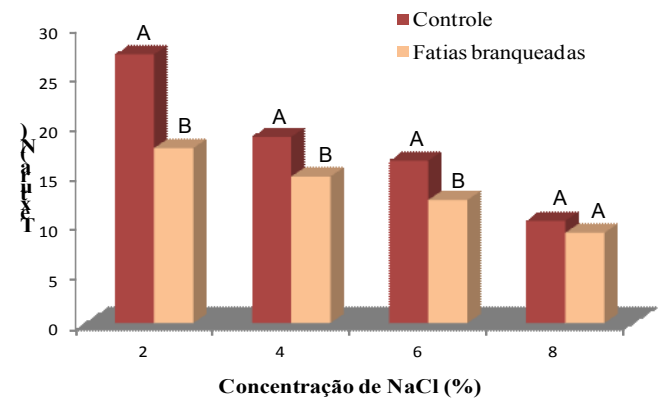

Figura 4. Valores médios da textura das fatias de cubiu durante o processo de fermentação natural.

As médias seguidas pela mesma letra não diferem estatisticamente entre si. Foi aplicado o Teste de Tukey ao nível de $5 \%$ de probabilidade.

Na Tabela 6, são apresentados os valores do teor de pectina das fatias de cubiu durante o processo de fermentação natural. Nota-se que houve diferença estatística significativa ao nível de $5 \%$ de probabilidade pelo teste de Tukey entre os tratamentos avaliados. Em ambos os tratamentos houve um decréscimo dos valores da pectina à medida que foram aumentando as concentrações das soluções de $\mathrm{NaCl}$. Os percentuais de redução ao fim do processo em relação à polpa in natura (Tabela 1) foram de 88,73 e $96,02 \%$ para o controle e branqueadas, respectivamente. As fatias que previamente não foram submetidas ao branqueamento (controle) apresentaram maiores valores.

Tabela 6 - Valores médios da pectina das fatias de cubiu durante o processo de fermentação natural.

\begin{tabular}{|c|c|c|}
\hline \multirow{2}{*}{$\begin{array}{l}\text { Concentração das soluções } \\
\qquad(\% \mathrm{NaCl})\end{array}$} & \multicolumn{2}{|c|}{ Pectina (mg/100 g de cubiu) } \\
\hline & Controle & Branqueadas \\
\hline 2 & $339,14 \mathrm{aA}$ & $230,71 \mathrm{aB}$ \\
\hline 4 & $161,30 \mathrm{bA}$ & 98,52 bB \\
\hline 6 & $105,97 \mathrm{cA}$ & $55,16 \quad \mathrm{cB}$ \\
\hline 8 & $83,91 \quad d A$ & $29,59 \quad \mathrm{~dB}$ \\
\hline
\end{tabular}

As médias seguidas pela mesma letra minúscula na coluna e maiúscula na linha não diferem estatisticamente entre si. Foi aplicado o Teste de Tukey ao nível de 5\% de probabilidade

\section{Discussão}

Se apresentou crescimento de microrganismos, em todos os meios de cultura, sendo as leveduras as que tiveram um maior desenvolvimento as 24 horas , mas as 48 horas o crescimento foi abundante independentemente do tratamento e do meio de cultura, indicando que o processo de fermentação natural se apresenta durante a imersão das fatias do cubiu em soluções de $\mathrm{NaCl}$, branqueada ou não.

A aplicação do branqueamento acarretou num aumento da umidade e $\mathrm{pH}$. No entanto, a acidez total, cloreto de sódio e a pectina sofreram um decréscimo, ocasionado pela dissolução na água durante o processo. A textura não sofreu alteração significativa, indicando o não cozimento devido ao curto tempo de branqueamento utilizado no experimento.

YUYAMA et al. (2008) encontraram para polpa de cubiu, valores de umidade e $\mathrm{pH}$ de $94,32 \%$ e 4,79 , respectivamente, os quais são superiores aos observados nessa pesquisa, isto se deve pela diferença nas características dos frutos do cubiu. Andrade Júnior (2006) encontrou um teor de pectina de 1,86 g/100g para uma porção de material integral (com casca, polpa e placenta) de cubiu maduro, sendo este valor muito superior ao encontrado neste estudo. Pode-se observar que o percentual de diminuição do teor de pectina foi de $25,93 \%$ após a aplicação do branqueamento. Este resultado era esperado, pois a fibra solúvel pode ser afetada pelas condições do processamento (MARINQUE e LAJOLO, 2001).

Em relação aos frutos in natura pode se observar um aumento dos teores de cloreto de sódio, decorrente das membranas celulares serem permeáveis aos íons $\mathrm{Na}^{+}$e $\mathrm{Cl}^{-}$(BORIN et al., 2008), permitindo assim, alta impregnação desse soluto.

Os maiores percentuais do cloreto de sódio foram encontrados nas fatias submetidas previamente ao branqueamento. Este comportamento está de acordo com HENG et at. (1990) quando dizem que, por aumentar a permeabilidade, e conseqüentemente, diminuir a seletividade celular, o branqueamento também pode favorecer o ganho de sólidos, pela incorporação de solutos durante posterior desidratação osmótica.

\section{Conclusões}

O processo de fermentação natural, modifica as características físicas e físico-químicas das fatias de 
cubiu, tais como, redução da umidade, textura e pectina, e acréscimo da acidez e cloreto de sódio, e uma leve tendência de aumento do $\mathrm{pH}$, sendo mais acentuadas nas fatias pré tratadas pelo branqueamento.

O branqueamento acarretou aumento dos valores da umidade e $\mathrm{pH}$, e decréscimo da acidez total, cloreto de sódio e pectina, enquanto a textura permaneceu inalterada.

A fermentação natural é eficiente na redução dos teores da pectina, podendo ser utilizada com pré tratamento da desidratação osmótica.

\section{Referências}

AGUIRRE, J.M. et al. 1982. Efeito do branqueamento na preservação das qualidades da cenoura desidratada. Boletim do Ital 19 (4): 403-422.

ANDRADE JÚNIOR, M.C. Mudanças dos Índices Físico-Químicos e Toxicológicos de Frutos de Cúbio (Solanum sessiliflorum Dunal) em Diferentes Estádios de Maturação. 2006. 128f. Dissertação (Mestrado em Ciência de Alimentos), Universidade Federal do Amazonas. Manaus, Brasil.

BORIN, I.; FRASCARELI, E.C.; MAURO, M.A.; KIMURA, M. 2008. Efeito do pré-tratamento osmótico com sacarose e cloreto de sódio sobre a secagem convectiva de abóbora. Ciência e Tecnologia de Alimentos 28 (1): $39-50$.

CANET, W.; ALVAREZ, M.D.; LUNA, P.; FERNÁNDEZ, C.; TORTOSA, M.E. 2005. Blanching effects on chemistry, quality and structure of green beans (cv. Moncayo). European Food Research and Technology 220 (1): $421-430$.

CANTOR, S.; MEREDITH, F.I.; WICKER, L. 1992. Postharvest Changes of Pectic Substances in Chilled Peaches. Journal of Food Biochemistry 16 (1): 15-29.

GAVA, M.A. 2002. Desempenho de diferentes meios de cultura utilizando na avaliação de fungos presentes em ambientes de produção de alimentos. 2002. 50f. Dissertação Mestrado em Ciências: Microbiologia Agrícola. Universidade de São Paulo. Piracicaba, Brasil.

GOMEZ CACERES, L.P. 2010. Otimização da desidratação do fruto do cubiu (Solanum sessiliflorum Dunal) utilizando solução ternária. 2010. 88f. Dissertação Mestrado em Agricultura no Trópico Úmido. Instituto Nacional de Pesquisas da Amazônia. Manaus, Amazonas.

GOMEZ-CACERES, L. et al. 2009. Alterações nas propriedades físico-químicas do cubiu pré desidratado em diferentes soluções seguido de secagem. In: WORSHOP AGRICULTURANO TRÓPICO ÚMIDO, 1. 2009. Manaus. Anais. 2009. CD.

GOMEZ-CACERES, L.; ANDRADE, J. S.; OLIVEIRA, F.M.N. de. 2008. Métodos de descasque e branqueamento para o cubiu (Solanum sessiliflorum Dunal), um fruto da Amazônia. In: CONGRESSO BRASILEIRO DE CIÊNCIA E TECNOLOGIA DE ALIMENTOS, 21 e SEMINÁRIO LATINO AMERICANO E DO CARIBE DE CIÊNCIA E TECNOLOGIA DE ALIMENTOS, 15. 2008, Belo Horizonte. Anais. 2008. CD

HENG, K.; GUILBERT, S.; CUQ, J.L. 1990. Osmotic dehydratation of papaya: influences of process variables on the product quality. Science des Aliments 10 (4):831-848.

INSTITUTO ADOLFO LUTZ. 2008. Normas analíticas. In: Métodos químicos e físicos para análise de alimentos.

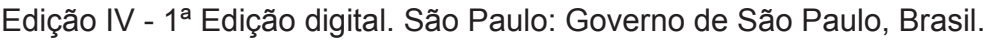

JACKIX, M. H. 1988. Doces, Geléias e frutas em calda (Teoria e prática). Campinas: Ícone, Brasil.

LUÍZ, R.C.; HIRATA, T.A.; CLEMENTE, E. 2007. Cinética de inativação da polifenoloxidase e peroxidase de abacate (Persea americana MILL.). Ciênc. agrotec., Lavras 31 (6):1766-1773. 
MACEDO, S. H.M. 1998. Caracterização físico-química e nutricional da polpa de cubiu (Solanum sessiliflorum Dunal) para aproveitamento industrial. 1999. 56f. Dissertação (Mestrado em Ciência de Alimentos), Universidade Federal do Amazonas. Manaus, Brasil.

MARINQUE, G.D.; LAJOLO, F.M. 2001. Maduración almacenamiento y procesamiento de frutas y vegetales: modificaciones em los componentes de la fibra soluble. Págs. 283-296. Em: Lajolo, F.M.; Calixto, F.S.; Penna, E.W.; Menezes, E.W. (Eds.) Fibra dietética em iberoamérica: Tecnologia y salud: otención, caracterización, efecto fisiológico y aplicación em alimentos. Livraria Varela. São Paulo, Brasil.

NIETO, A.; CASTRO, M.A.; ALZAMORA, S.M. 2001. Kinetics of moisture transfer during air drying of blanched and/ or osmotically dehydrated mango. Journal of Food Engineering 50:175-185.

OLIVEIRA, D.A. 2002. Caracterização bioquímica da peroxidase e efeito do tempo de branqueamento na qualidade e aceitabilidade da polpa de cubiu (Solanum sessiliflorum Dunal). 2002. 100f. Dissertação Mestrado em Ciência de Alimentos. Universidade Federal do Amazonas. Manaus, Brasil.

OLIVEIRA, F.M.N. de; ANDRADE, J.S.; GOMEZ-CACERES, L. 2008. Influência do Branqueamento nas Características do Cubiu (Solanum sessiliflorum Dunal) Desidratado. In: CONGRESSO BRASILEIRO DE CIENCIAE TECNOLOGIA DE ALIMENTOS, 21 e SEMINÁRIO LATINO AMERICANO E DO CARIBE DE CIÊNCIA E TECNOLOGIA DE ALIMENTOS, 15. 2008, Belo Horizonte. Anais. 2008. CD

OLIVEIRA, H. P. 1999. Elaboração de néctar de cubiu (Solanum sessiliflorum Dunal) e avaliação das características físico-químicas e sensoriais durante o armazenamento. 1999. 90f. Dissertação. Mestrado em Ciência de Alimentos. Universidade Federal do Amazonas. Manaus, Brasil.

SANTOS, J. W. DOS; GHEYI, H. R.. 2003. Estatística experimental aplicada: tópicos de engenharia agrícola e agronômica. Marcone. Campina Grande, Brasil.

SILVA, FILHO D.F.; YUYAMA, L.K.O.; AGUIAR, J.P.L.; OLIVEIRA MASLOVA, C.; MARTINS, L.H.P. 2005. Caracterização e avaliação do potencial agronômico e nutricional de etnovariedades de cubiu (Solanum sessiliflorum Dunal) da Amazônia. Acta Amazonica 35 (4):399-406.

SILVA, F.A.S.; AZEVEDO, C A.V. 2002. Versão do programa computacional Assistat para o sistema operacional Windows. Revista Brasileira de Produtos Agroindustriais 4 (1):71-78.

SOUTHGATE, D.A.T. 1991. Determination of food carbohydrates. 2ª Edição. Applied Science. London.

YUYAMA, L.K.O.; MACEDO, S.H.M.; AGUIAR, J.P.L.; FILHO, D.S.;

YUYAMA, K.; FÁVARO, D.I.T.; VASCONCELLOS, M.B.A.. 2007. Quantificação de macro e micro nutrientes em algumas etnovariedades de cubiu (Solanum sessiliflorum Dunal). Acta Amazonica 37 (3):425-430.

YUYAMA, L.K.O.; PANTOJA, L.; MAEDA, R.N.; AGUIAR, J.P.L.; SILVA, S. B. da.. 2008. Desenvolvimento e aceitabilidade de geléia dietética de cubiu (Solanum sessiliflorum Dunal). Ciência e Tecnologia de Alimentos 28 (4): 929-934. 